\title{
Homosexuality and the medical profession: A behaviourist's view
}

\author{
John Bancroft The Department of Psychiatry, University of Oxford
}

That a homosexual - man or woman - is neither a sinner nor a sick person is the thesis of this paper by an authority on sexual deviation. Therefore, such a man or woman neither needs penance and pardon nor cure in the medical sense. Nevertheless such individuals sometimes need the help of doctors and must be treated with understanding. The medical profession also has, in the view of the behaviourist school of psychiatrists, of which Dr Bancroft is a member, the duty of influencing social attitudes towards homosexuals. Obviously homosexuals who come into conflict with the law are special cases, and must be treated as such but this is not 'medical' treatment so much as social control even if drugs and other forms of therapy are used.

Homosexuality is no longer regarded as an illness by the majority of the medical profession. This represents a fairly recent change in medical thinking, however, and it is appropriate and timely to reappraise the role of the profession in relation to homosexuality. Should homosexuality be regarded as a medical issue at all? Has the profession any special responsibilities in this respect? In this paper I will consider the role that the medical profession should have in influencing public opinion, the traditional role of the doctor in helping the individual with homosexual problems and how these two roles might interact or conflict with one another.

\section{Homosexuality is not an illness}

I accept that homosexuality is not an illness but an alternative sexual life style which may be and often is compatible with normal health, and with those interpersonal and social values that we hold most high. If that is so then the social stigma associated with homosexuality, the repression that stems from it and the guilt and suffering that often result are undesirable and unjust. When we consider the part that the medical profession has played in the past in fostering these negative and unjust social attitudes it is clear that it has a responsibility now and in the future actively to encourage a more positive and less repressive climate of opinion. Obviously there are socially harmful forms of sexual behaviour which will inevitably and justifiably remain or become stigmatized, but they will be characterized by criteria other than the sex of the partner and will involve heterosexuals $a \vec{D}$ much as, if not more than, homosexuals.

\section{The role of the doctor}

The help given by the doctor to the individual with homosexual problems can be of three types. First. facilitating the individual's adaptation to a homos sexual role; helping him or her to cope with the stigmatizing consequences of the role, reducing unjustified guilt and helping with interpersonal ow sexual problems arising in the homosexual relations ship. This type of help in no way conflicts with th: doctor's first role, that of modifying social attitudes in fact it is consistent with and complements it. Although such help may involve the treatment $\overrightarrow{\sigma \Phi}$ illness - some homosexuals become very depressech as a result of their social and interpersonal problems - most of it can be seen as counselling or psycho therapy which could equally well be provided bo other helping professionals with appropriag experience.

At the present time the majority of doctors wh are not themselves homosexual in orientation ar ill equipped or ill disposed to provide such help Fortunately there is a gradual increase in the availability of counselling of this type but it is by no means adequate as yet.

There are two further types of help: with one the individual with either homosexual or uncertai sexual preferences is helped to explore and establisi heterosexual relationships. With the other he is helped to gain self control over certain aspects of his behaviour which would otherwise get him in trouble with the law. This help is not necessarig medical but for the time being the medical profession must be regarded as one of the important sources of such help. In both cases, however, the doctor is likely to be attacked for providing it.

Historical development of social and medical attitudes to homosexuality

In understanding such criticism and attack it $\stackrel{\overrightarrow{i s}}{\mathrm{f}}$ helpful to consider briefly the historical develop ment of social and medical attitudes to hom $\overrightarrow{8}$ sexuality. In doing so it becomes clearer ho society's evaluation of homosexuality has beconfe entangled with the medical profession's approaet to treating it. 
It is probably true to say that the institution that originally had most influence on the social attitudes to homosexuality was the Church. It has been suggested that some of the intensity of the Church's attack on homosexuality stemmed from its fear of such behaviour amongst its own members - a kind of institutional 'reaction formation' (Taylor, 1954). By the late eighteenth century, however, the medical profession was beginning to 'medicalize' the Church's sexual morality. Initially this attack was on any form of 'non-procreative' sex, masturbation and homosexuality being especially implicated (Bullough, 1974). Such sex was considered as being exceedingly harmful to health. The medical emphasis was on the harmful effects rather than the pathological causation.

In the mid-nineteenth century, people such as Karl Ullrich started to defend homosexuals. Medical opinion became somewhat polarized into those who sought to tolerate such variants of human behaviour and those who condemned them as fundamentally sinful. The split reflected the general divergence of more humanitarian and more oppressive attitudes to various kinds of deviant behaviour, including insanity.

Those doctors who chose to defend the homosexual sought ways of reducing his culpability by explanations which initially invoked congenital anomaly or 'congenital reversal of sexual feeling' and later, according to the Freudian view, arrested development at an early age. In neither case could the homosexual be considered responsible and therefore could not justifiably be punished for his state.

This attitude has extremely important implications so far as treatment is concerned. If homosexuality or other comparable behaviour patterns are modifiable either by treatment or education, this in some important but not entirely logical way weakens the view that the individual can avoid responsibility for them. Even if he escapes responsibility for his earlier development he would not be able to deny responsibility for obtaining treatment if it is shown to be effective. A corollary is that because congenital conditions are presumably immutable (an unjustified but widely held assumption) then the mutability of homosexuality means that it is acquired and consequently in the same category as a vice. Thus it is not surprising that early attempts to modify homosexual behaviour, though modestly successful, were heavily attacked by those defending the general cause of the homosexual.

The moralizing and oppressive tones of the 'tough minded' continued and reached a twentieth century sophistication in the edicts of the mental hygiene movement, attaining its medical zenith as recently as 1955 with the evidence of the British Medical Association to the Wolfenden Committee on homosexuality and prostitution (BMA, 1955). Fortunately the fact that the Wolfenden Committee was created was an indication that more enlightened spokesmen, some of them medical, were beginning to have an effect.

Public attitudes to homosexuality in Britain were reflected in public opinion polls of the late 505 and 60 . Changes were occurring but very much in a manner that Barbara Wootton (1966) described as 'the concept of illness expanding at the expense of the concept of moral failure' - people were tolerating homosexuals more by deeming them ill. This was little comfort to the homosexuals; as Altman (I97I) put it, 'To be viewed as ill rather than evil is not much consolation, for it represents an attempt to destroy an individual's identity that is as brutal in a subtle way as is imprisonment'. From deeming the homosexual ill, the logical step was to urge him to be treated. The fact that round this time both psychoanalytic and behavioural psychotherapists were starting to claim successes in helping homosexuals to become heterosexual, and often doing so under the rubric of medical treatment, fed fuel to this fire which not unnaturally angered those homosexuals who sought to improve their stigmatized position in society. Psychiatry and behaviour therapy came in for heavy attack as evidenced in the gay liberation pamphlet Psychiatry and the homosexual: a brief analysis of oppression (Gay Liberation, 1973).

The Wolfenden Committee (1957) debated whether homosexuality was an illness and concluded that it was not. Though principally concerned with deciding whether homosexuality should be treated, they apparently overlooked the possibly more important issue of the effect of the 'illness concept' on public attitudes and were seemingly unaware that 'treatment', if defined as help given by clinical professionals, does not necessarily imply illness.

\section{The present situation}

Since that time the main weight of medical and psychological writing on the subject has rejected the illness explanation, and in 1974 the American Psychiatric Association removed homosexuality from its list of psychiatric diseases. Homosexuals have been organizing themselves into groups for some time but in parallel with these developments in medical thinking, gay groups have become much more active and militant, intent on improving the position of the homosexual in society.

Nevertheless individuals continue to seek help to become more heterosexual or to curb the less controlled or socially dangerous aspects of their sexuality. In the United Kingdom this help is mainly provided by psychiatrists and clinical psychologists using a behavioural approach to treatment. Not surprisingly such help still provokes considerable hostility amongst gay groups. The earlier objections remain. The implication that because homosexual preferences can be modified 
then all homosexuals have a responsibility to seek such modification is still a threat to homosexual freedom. The fact that most people giving such help explicitly reject such an idea unfortunately does not satisfy such critics. The idea of 'treatment' still implies some concept of illness or pathology. The stated principles of the modern behaviour therapists are in fact quite explicitly to the contrary. Whereas early behavioural methods, such as aversion therapy, were aimed at a general suppression of homosexual feelings, as if they were something that should be got rid of, the emphasis is now on helping the individual to learn new and rewarding forms of sexual behaviour (Bancroft, 1974). The approach is educational rather than curative, positive rather than negative. Aversive methods, if they are used at all, are used to facilitate self control in those whose behaviour would otherwise get them into trouble with the law.

Unfortunately in both respects the behaviour therapist escapes from one attack only to step into another. If he is not treating 'illness' he is persuading people to conform to society's standards. This not only raises strong objections among gay people themselves, who see this as a continuing reinforcement of negative social attitudes to homosexuality, but it also elicits protests from some non-gay people who object to any apparent acceptance of the status quo of a social system which they would like to see radically altered (eg, Taylor, 1974) or who fear the power of applied psychology, seeing it as a potential tool for evil forms of social control. Whereas one can understand and accept this fear when the use of drugs or psychosurgery is involved, it is of interest that behaviourism has provoked it so much more than other methods of psychological treatment such as psychoanalysis. This fear cannot be based on a rational appraisal of the effects which, whilst being marginally greater than those produced by other forms of psychotherapy, are in any case confined within limits set by the individual himself. 'Brain washing' and thought reform, if they work at all, do so in situations where the individual has absolutely no control over his environment or his safety. The blame for much of this unease about behavioural methods must, I think, lie with us behaviourists who in pursuit of heuristic models have systematically dehumanized our theoretical formulations of the patient-therapist relationship and have thus allowed non-behaviourists to see us as inhumane. In our actual contacts with patients or clients we are no less compassionate or caring than any other group of helping professionals. In the future we must pay much more attention to public relations if we expect to extend constructively our influence in society.

This image of the inhumane, controlling behaviourist fosters the idea that individuals seeking such help are not in fact wanting it but are being pressurized by society or the therapist into ac- cepting it. Any statement by the patient to the contrary is rejected as being 'compliant'. This is af type of argument that evades any logical countere and is easier to sustain if its proponent is not: actually confronted by an individual earnestly? seeking help. Obviously it is the therapist's re=o sponsibility to ensure that this is the type of helpo his patient wants and that he is not seeking is? because of external pressures. Homosexuals ar@ subjected to many types of oppression: one of then most hostile can be the attitude, 'You are a homo-' sexual - you must learn to accept it'.

Nevertheless, it should also be said that gay organizations' attempts to improve their lot and too counter negative public attitudes have under $\overline{\overline{3}}$ standably, though regrettably, led them to reject any evidence which suggests that there is mobility between homosexual and heterosexual roles. Their hostility to the increasing acceptance of bisexualityo in certain subcultures is further evidence of this.

\section{Conflict with the law}

Where the doctor's role is to help the individua $B$ to avoid conflict with the law, the objection is that the laws are wrong and the therapist is reinforcing an oppressive legal system by encouraging they individual to conform to it. I would agree that both ${ }^{\mathrm{V}}$ the law and the way that it is exercised discriminates unfairly against the homosexual and needs further revision. I also believe that if there is a need for laws of any kind, then there is a need for proscriptiong of certain types of sexual behaviour both homo $\mathbb{D}$ sexual and heterosexual. In any case, until the tims that the law is changed, are we to encourage every 3 threatened individual into the role of a martye which nearly always he would rather avoid? I anp referring here to the individual's self control - his ability to avoid breaking the law when he would prefer to avoid doing so and the therapist's attempts to help him. I am not referring to the control of his behaviour that is imposed upon him by theo machinery of law, that is social control not self control; a legal but not a medical matter, everf when drugs or other kinds of medical expertise ares used for the purpose. This is a further area of confusion for which the medical as well as the legal, profession must be held largely responsible. Mucl? medical writing on the subject has failed to make the crucial distinction between therapy and social control (eg, Karpmann, 1954). Anyone reading such literature would be justified if they saw the seeds of political abuse of which one hears in some totalitarian states where political deviants? are controlled by medical methods under the guiseo of psychiatric treatment.

\section{The 'treatment' of homosexuality}

Of these various objections to 'treating' 
homosexual, the one that requires most serious consideration is that by providing such treatment the therapist is reinforcing negative social attitudes. This at first sight is a dilemma between influencing social change in a positive way and helping the distressed individual. My answer to this objection and my reasons for refuting the existence of a real dilemma depend on our current lack of understanding of the determinants of sexual orientation and role. If there was any evidence that homosexuality was invariably a fundamental characteristic of the person that was both incompatible with heterosexuality and immutable, then there would be justification for rejecting such help on the grounds that not only was it imposing something unnatural on the individual but also that by doing so it was rejecting any positive attributes of the homosexual role. But there is no such evidence. It is probably true that a substantial majority of homosexuals for most of their adult life have no desire to change their sexual orientation and are not likely to seek such help in any case. It is also an unquestionable fact that many go through a phase of homosexuality before adopting a bisexual or a predominantly heterosexual role and many do the reverse. In most cases this is without professional help. During the period of their lives in which they undergo such transition, they will be facing problems in a similar way to those who come seeking help from clinicians. They may be uncertain of what is best for them sexually or they may at the time reject the homoor heterosexual part of themselves and seek an alternative self image and role. Such individuals in a state of uncertainty are especially vulnerable to social pressures. There are the pressures from heterosexual society telling them that homosexuality is bad, pathological, perverse. There are also the pressures, increasing in power from the gay community, telling them that if they have any homosexual feelings they are homosexual and should accept the fact. Their heterosexual feelings and aspirations, they are told, are simply products of social pressures to conform. They are subjected to a vigorous, proselytizing campaign, rejecting even the notion of bisexuality. A Gay Lib pamphlet made the following comment: 'Any one who is sufficiently worried about their homosexual feelings to consult a doctor about the problem is definitely homosexual.'

It is an ironic, if understandable, fact that the more militant and vocal part of the homosexual community is imposing the same type of constraint on individual sexual freedom as they bitterly and justifiably complain is imposed upon them.

The justification for attempting to influence public opinion, that I have already claimed as a responsibility of the medical profession, stems from support for the freedom of the individual to follow whatever pattern of sexual life style is both adaptive for him and compatible with the interests of others in his social group. It also stems from the rejection of social prejudices that are either unjust or outdated. It is entirely consistent for the professional at the same time to help the individual to explore different types of sexual relationship before recognizing what he or she is happiest with. Although many of us will adopt one sexual role or another quickly, and rarely with any doubt, there are others who need time. During that time they may benefit not only from the counselling which facilitates rewarding sexual relationships but also from protection from pressures to conform and to resolve prematurely their uncertainty, whether they be from 'straight' or 'gay' sources.

Whatever form 'treatment' has taken in the past, this is the approach that I would advocate and justify today; help and encouragement in establishing a rewarding sexual relationship whether it be homoor heterosexual and in using sex as a method of communication and a binding force in interpersonal relationships rather than simply as a source of individual pleasure; and where the individual is unsure, help in exploring different types of relationship; help in getting into perspective what is good and bad about sex.

\section{Conclusions}

Let me conclude by summarizing.

r) Homosexuality can be and often is a form of interpersonal sexual relationship that is as personally rewarding and socially beneficial as the best examples of heterosexuality. The medical profession has a responsibility to influence public (and medical) opinion so that individuals are not stigmatized for being homosexual per se. Sexual values should be concerned with the quality of the interpersonal relationship rather than the gender of its participants.

2) Many individuals seek and may benefit from professional help in exploring and establishing the sexual role that is best for them. At the present time such individuals are under pressure to conform from both hetero- and homosexual groups and need protection from these pressures.

3) Some individuals seek and need help to control certain aspects of their sexual behaviour which would otherwise get them into trouble with the law.

4) Behaviourally orientated therapists, who may be medically qualified, can help in both ways but only in the context of a mutually accepting and trusting relationship in which the patient or client is not treated as ill and carries the final responsibility for choosing the goals of such help.

5) Social control of sexual offenders by the courts should not be regarded as medical treatment even when drugs or other forms of medical expertise are made use of.

6) Behaviour therapists should take care not to 
represent themselves to others in a misleadingly inhumane light by their use of dehumanizing theoretical models and technical jargon. In an emotive area such as this there is much scope for misunderstanding.

\section{References}

Altman, D (1971). Homosexual oppression and liberation. Allen Lane, London.

Bancroft, J H J (1974). Deviant sexual behaviour: Modification and assessment. Oxford University Press.
BMA (1955). Memorandum on homoseruality and prostitution drawn up by a special committee of the British Medical Association, London.

Bullough, V L (1974). Homoserunlity and the medicat model. Foumal of Homosexuality, I, 99-1 10.

Gay Liberation (1973). Psychiatry and the homosexual A brief analysis of oppression. Gay Liberation Pamphlet, No I, Pomegranate Press.

Karpmann, B (1954). The sexual offender and $h$ 通 offences. Julian Press, New York.

Taylor, G R (1954). Sex in history. Ballantine Books New York.

Taylor, L (1974). Review of Deviant sexual behaviour by J H J Bancroft. In New Society, I9 Septembep? I974. 